\title{
Testing the single-pass VOC removal efficiency of an active green wall using methyl ethyl ketone (MEK)
}

\author{
Fraser Torpy $^{1}\left(\mathbb{D} \cdot\right.$ Nicholas Clements $^{2,3,4} \cdot$ Max Pollinger $^{5} \cdot$ Andy Dengel $^{6}$. \\ Isaac Mulvihill ${ }^{5}$ Chuan $\mathrm{He}^{2,3,4} \cdot$ Peter Irga $^{1}$
}

Received: 21 June 2017 / Accepted: 18 September 2017 /Published online: 27 October 2017

(C) The Author(s) 2017. This article is an open access publication

\begin{abstract}
In recent years, research into the efficacy of indoor air biofiltration mechanisms, notably living green walls, has become more prevalent. Whilst green walls are often utilised within the built environment for their biophilic effects, there is little evidence demonstrating the efficacy of active green wall biofiltration for the removal of volatile organic compounds (VOCs) at concentrations found within an interior environment. The current work describes a novel approach to quantifying the VOC removal effectiveness by an active living green wall, which uses a mechanical system to force air through the substrate and plant foliage. After developing a single-pass efficiency protocol to understand the immediate effects of the system, the active green wall was installed into a $30-\mathrm{m}^{3}$ chamber representative of a single room and presented with the contaminant 2-butanone (methyl ethyl ketone; MEK), a VOC commonly found in interior environments through its use in textile and plastic manufacture. Chamber inlet levels of MEK remained steady at $33.91 \pm 0.541$ ppbv. Utilising a forced-air system to draw the contaminated air through a green wall based on a soil-less growing medium containing activated carbon, the combined effects of substrate media and
\end{abstract}

Fraser Torpy

fraser.torpy@uts.edu.au

1 Plants and Environmental Quality Research Group, School of Life Sciences, Faculty of Science, University of Technology Sydney, Sydney, Australia

2 Well Living Lab, Rochester, MN, USA

3 Delos Labs, Delos, New York, NY, USA

4 General Internal Medicine, Mayo Clinic, Rochester, MN, USA

5 Delos, New York, NY, USA

6 Building Research Establishment, Watford, UK botanical component within the biofiltration system showed statistically significant VOC reduction, averaging 57\% singlepass removal efficiency over multiple test procedures. These results indicate a high level of VOC removal efficiency for the active green wall biofilter tested and provide evidence that active biofiltration may aid in reducing exposure to VOCs in the indoor environment.

Keywords Biofiltration · Indoor air · Indoor plants · Air pollution $\cdot$ CADR $\cdot$ Phytoremediation

\section{Introduction}

Air pollution is a major worldwide public health issue, with air pollution exposure attributed to seven million deaths globally in 2014 (World Health Organisation (W.H.O) 2014). Whilst a portion of an individual's pollution exposure is directly linked to outdoor air (Lawin et al. 2017), a growing body of evidence identifies indoor air pollutants as having significant health impacts on humans within the built environment (Gibson et al. 2013), spaces in which contemporary urban populations spend $90 \%$ of their lives (EPA 2014). Volatile organic compounds (VOCs) are largely anthropogenic pollutants commonly associated with poor-quality indoor air (Lai et al. 2004; Lu et al. 2012; Steinemann 2015; Su et al. 2011). The health effects of VOC exposure are well studied (Rumchev et al. 2004); many VOCs are labelled as category 1 human carcinogens (Bernstein et al. 2008; Mitchell 2013). Consequently, there is a priority to reduce VOC exposure in the built environment (Ayala et al. 2012).

Whilst many filtration technologies exist for reducing indoor VOCs, including adsorption filters, photocatalytic oxidation purifiers, ozone generators, and ionisers (Ren et al. 2017; Zhang et al. 2011), such techniques are often 
expensive, remove a constrained range of VOCs, and can produce harmful by-products (Revah and MorganSagastume 2005). The development of indoor air phytoremediation technologies may lead to an economical and sustainable departure from these conventional techniques, with potential for incorporation into the built environment for the amelioration of indoor VOC concentrations (Rodgers et al. 2012; Siswanto et al. 2016). Most research on indoor air phytoremediation has focused on potted plants (Aydogan and Montoya 2011; Irga et al. 2013; Kim et al. 2016; Orwell et al. 2006; Xu et al. 2011; Wolverton et al. 1989). This research has identified the substrate microbial community as the primary agents of VOC removal, with an 'induction' phase required before maximal biodegradation performance is attained (Orwell et al. 2004). However, active botanical biofiltration technology, specifically forced-air biowall systems, has received far less research. The increased plant density, vertical alignment, and high volume exposure of the plant growth media to the atmosphere are all advancements on traditional potted plant arrangements (Torpy et al. 2016). Functionally, these systems facilitate the movement of polluted air through the plant root systems and growing media and rely on a combination of plant leaves, rhizospheric microorganisms, and the chemical and physical properties of the media to adsorb or absorb pollutants from indoor air and biodegrade them in situ (Soreanu et al. 2013).

The majority of existing literature demonstrating that indoor vegetation can remove VOCs from indoor air has been conducted utilising small-scale in vitro experimental set-ups, constraining the generalisation of their findings to real-life settings (Dela Cruz et al. 2014a; Thomas et al. 2015). These experiments commonly involve injecting a single pulse of surrogate VOC (usually benzene, toluene, or formaldehyde) into a sealed, static chamber and recording the decay of VOC concentration over time and have often utilised initial VOC concentrations that are substantially higher than those found in situ (Waring 2016). It has been demonstrated that the performance of air cleaning media at high VOC concentrations cannot directly reflect their performance at the typical indoor concentration (Zhang et al. 2011), thus limiting the reliability of some previous findings.

With the development of active botanical biofiltration, there is a growing requirement to assess the functional performance of these systems and develop metrics to enable comparison to existing systems (Waring 2016). Whilst many metrics (e.g. clean air delivery rate; CADR) could be calculated from static chamber test decay curves, the chamber-toroom volume ratios utilised in many experiments are too small to be representative of in situ functional VOC removal. Additionally, it is possible that calculated VOC removal rates may be lower for experiments testing a single pulse of VOC than those using exposure to a continuous VOC levels (Dela
Cruz et al. 2014b). Moreover, single-pass removal efficiency experiments may be more representative of the efficiency of a system in use, where VOCs are continuously emitted from their sources at relatively stable concentrations, thus presenting a constant pollutant input to the biofilter. Static chamber studies thus provide a test of the efficacy of a system to draw down pollutants, but do not provide information on their quantitative efficiency.

The work presented here demonstrates a methodological approach to quantifying the filtration efficiency of active botanical biofiltration systems, which could allow different systems to be objectively compared. The methodology is applied to the testing of a commercial device in a controlled, realistically sized chamber for the phytoremediation of methyl ethyl ketone (MEK) at concentrations of in situ relevance. In the current work, the combined VOC removal effects of the substrate media and botanical component were tested together, representative of the overall functional performance of the biowall in situ. Authenticated international standards were employed to enable relative methodological comparisons for future work validating the function of active green wall biofiltration.

\section{Methods and materials}

\section{Biofilter}

The biofiltration system used in these trials was a commercial active living wall biofilter (Naava One system, Naturvention Pty, Jyväskylä, Finland; Fig. 1), which is a free standing indoor plant wall. The system is composed of two functional components: (1) an inorganic growing media to support plant viability, along with activated carbon to assist in VOC removal, which acts as a biofilter through which ambient indoor air is drawn with an integral electric fan, and (2) the system holds 63 plants which grow horizontally from circular compartments in the front vertical face of the casing, which is $150 \times 100 \mathrm{~cm}$ in area. The plant species used in the experimental green wall units were 18 individual Philodendron scandens, 13 Philodendron scandens 'Brazil', 19 Asplenium antiquum, and 13 Syngonium podophyllum. These plant species are popular in indoor plant wall arrangements and were selected on this basis alone, rather than their ability to remove VOCs. The size of the plants was such that the combined foliage completely covered the front face of the plant wall casing. The airflow rate through the plant wall was set at $50 \mathrm{~m}^{3} \mathrm{~h}^{-1}$, with air flowing through the foliage and substrate and into an exhaust duct at the top of the wall. In normal use, effluent air is returned to the room, whereas in the experimental system, it was ducted from the test chamber for testing. The growing media moisture content was increased to saturation twice daily, with manual watering at 05:00 and 17:00. 
Fig. 1 Schematic of the botanical biofiltration system tested and photograph of the fully assembled system. The plants displayed in the photograph of the botanical biofilter differ from those described in the current work
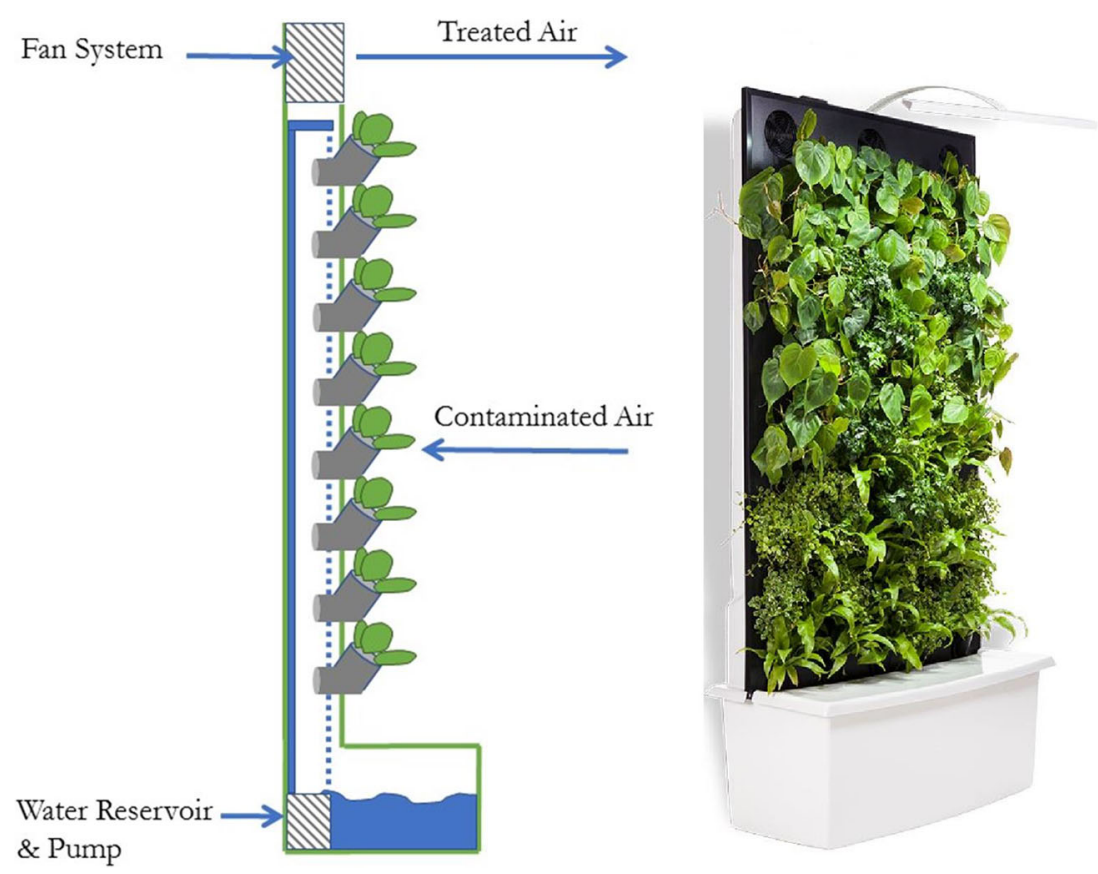

In order to validate the test methodology and removal performance, MEK was selected as the challenge gas in this study. MEK is a VOC that is commonly found in interior environments through its use in textile and plastic manufacture, and outgassing from printed and painted materials (Zaleski et al. 2007). MEK's molecular weight is 72.1057 , vapour pressure is 74 Torr at $20{ }^{\circ} \mathrm{C}$, solubility in water is $24.0 \%$ at $20^{\circ} \mathrm{C}$, and Henry's Law constant is $4.67 \times 10^{-5} \mathrm{~atm}-\mathrm{m}^{3} / \mathrm{mol}$. Exposure to MEK vapour causes upper respiratory tract irritation at $100 \mathrm{ppmv}$, eye irritation at $200 \mathrm{ppmv}$, headache at $300 \mathrm{ppmv}$, and severe symptoms including paraesthesia at 300-600 ppmv (Zaleski et al. 2007). The current permissible occupational exposure limit for MEK is $200 \mathrm{ppmv}$, as an 8-h time-weighted average (Occupational Safety and Health Administration (OSHA) 2017). The odour threshold of MEK is 5 ppmv, which is well below the recommended exposure limit; thus, it is treated as a chemical with adequate warning properties (Centres of Disease Control and Prevention (CDC) 2017). It was used in this study as a VOC of concern to human health through occupational exposure and is a VOC that has received relatively little prior study. The MEK concentration used for these tests (30 ppbv) was selected to represent the relative occupational exposure concentrations likely to be found in indoor environments. Such VOC levels are nonetheless of considerable health concern, as long-term, low concentration exposure to VOCs has been linked to pulmonary problems in both mice (Wang et al. 2014) and humans (Arif and Shah 2007). MEK exposure alone shows low acute and subchronic toxicity but, when combined with other substances as is often the case in situ, it can exacerbate their toxicity (Cosnier et al. 2017). For example, it has been demonstrated that MEK facilitates the hepatotoxic effects of carbon tetrachloride (Goldstein et al. 2013).

\section{Chamber set-up and operation}

The environmental chamber used for testing (Fig. 2) was built to the 'European reference room' specifications given in CEN/TS 16516 (CEN/TS 2013). The chamber had a volume of $30.0 \mathrm{~m}^{3}$ $(4.0 \times 3.0 \times 2.5 \mathrm{~m}$ high $)$ and was constructed from structural insulation panels with food grade painted steel wall and ceiling surfaces and an aluminium floor, so as to minimise VOC emissions or sorption. The chamber walls were $80 \mathrm{~mm}$ thick. Temperature and humidity were continuously monitored using Vaisala HMP110 Humidity and Temperature Probes (Vaisala Oyj, Helsinki, Finland) and controlled to $21.5 \pm 2{ }^{\circ} \mathrm{C}$ and $37.5 \pm 2.5 \% \mathrm{RH}$. The ventilation rate in the chamber was controlled to within $4 \%$ of the target value of $50 \mathrm{~m}^{3} / \mathrm{s}$ or 1.67 air changes per hour $(\mathrm{ACH})$ by maintaining the airflow rate of the supply via a low-level 150-mm diameter stainless steel horizontal air discharge valve, using an orifice plate flow control system. Air was exhausted via a plenum fixed to the top of the green wall and then to a 150-mm stainless steel duct. Exhaust airflow from the green wall was monitored via TSI Venturi model No: 2017 inline venturi and a CMR Controls pressure sensor was used to set the airflow over the green wall in the chamber. These instruments were calibrated as a system using a Chell Mass Flow Meter over their full working range prior to experimentation. The control system maintained the room at $+4 \mathrm{~Pa}$ pressure difference relative to the outside. Chamber air mixing was accomplished using two small oscillating fans.

A LED floodlight was mounted on a stand $0.80 \mathrm{~m}$ from the green wall to give an average illuminance of approximately 2500 Lux ( $40 \mu \mathrm{mol} \mathrm{s}{ }^{-1} \mathrm{~m}^{-2}$ photosynthetically active radiation) at the green wall for an $18 \mathrm{~h}$ day $^{-1}$ photo-period. Lighting was controlled remotely by mobile phone signal (Naava Family Phone 
Fig. 2 Schematic of the test chamber. VOC concentrations were monitored at both chamber inlet and outlet during the trials $\begin{array}{lll}\text { (1) Air Sampling for MEK (Ingoing Stream) } & \text { (2) Air Sampling for MEK (Outgoing Stream) }\end{array}$

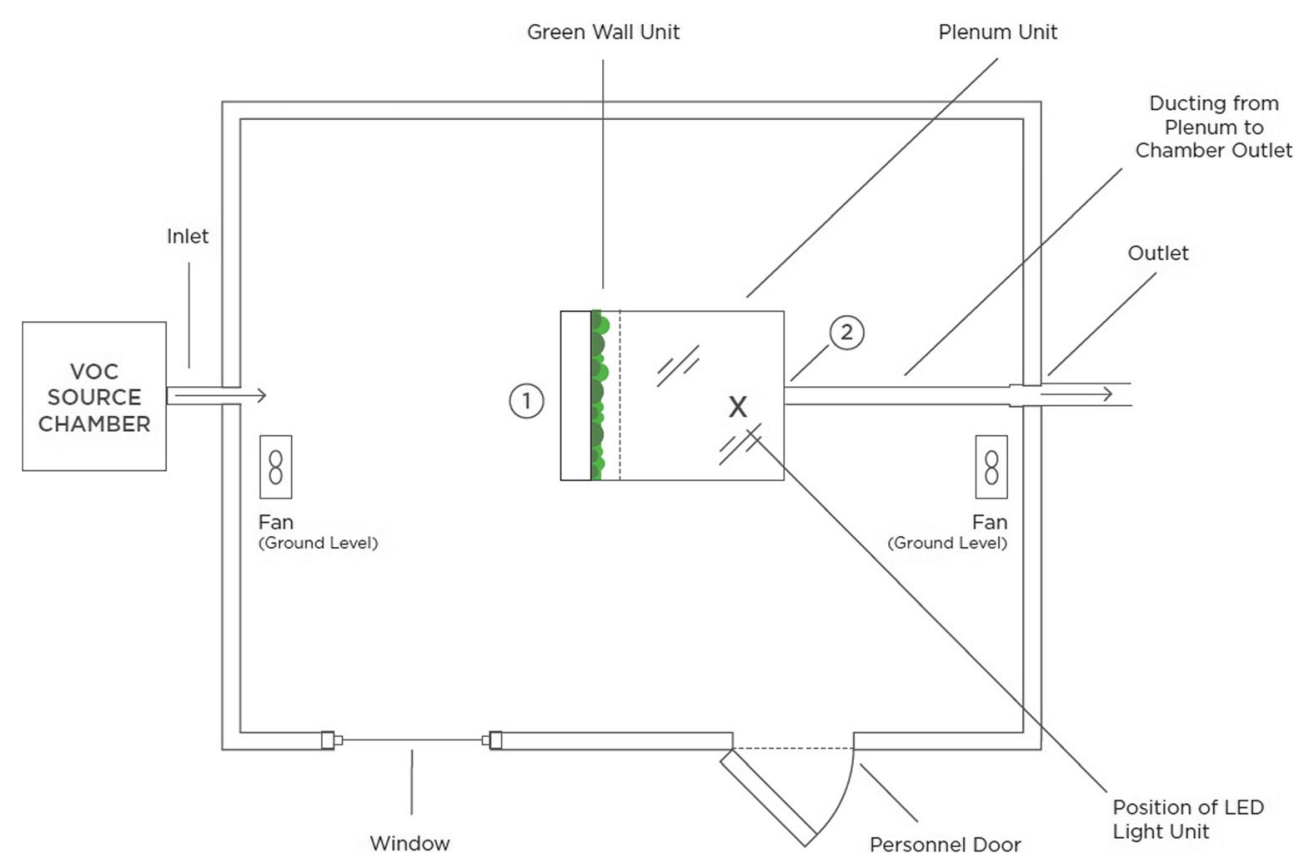

app, Helsinki, Finland), as were plant watering and green wall ventilation fans. An additional heat source matching the LED heat input to the room was used during the LED off periods to maintain a constant load on the ventilation system for the duration of the test.

To enable the introduction of a controlled concentration of airborne MEK, air was drawn through a separate upstream source chamber using the main chamber air handling system. Sources of MEK were trialled with the aim of providing a reasonably stable source of the compound at the required concentration in the chamber at an airflow rate of $50 \mathrm{~m}^{3} \mathrm{~h}^{-1}$ (i.e. $1.67 \mathrm{ACH}$ in the $30 \mathrm{~m}^{3}$ chamber space). The MEK source used for the trials utilised an in-house wicking system, consisting of the solvent in $25 \times 0.8 \mathrm{~cm}$ internal diameter steel tubes with 10-mm-long, 10-mm-diameter silicon sponge cord. One silicon sponge cord was used per tube. MEK was introduced to the chamber at the required level using one of two separate upstream source chambers developed and used in the course of the EC FP7 'ECO-SEE' research project (Da Silva et al. 2016). One source chamber was stand-alone and used to verify the source emission rates, and the other was connected to the main chamber air handling system for doping the chamber air. The gas inlet was $0.3 \mathrm{~m}$ above the floor of the chamber, and the outlet was $0.3 \mathrm{~m}$ below the ceiling of the chamber.

\section{Test protocol}

The experimental sequence was repeated in full three times, with new plants in the green wall unit for each sequence during step (b), followed by a 3-day acclimation period with the fresh plants before testing in step (c). a) Chamber loss trial (empty green wall). The empty green wall unit was comprised of the outer casing only, completely empty of growing medium and water. The chamber ventilation system was operated for $4 \mathrm{~h}$ with the MEK source on. Air sampling was performed from ingoing and outgoing gas streams (one sample from each). The chamber loss trials were the reference samples against which plant wall bioremediation activity was compared; thus, the plant wall effect includes both plant and substrate activity. We did not use a substrate only reference sample as the relative effects of substrate and botanical components of the system were not of interest in the current work.

b) Installation of fresh plants in the green wall unit.

c) Acclimatisation period. Green wall unit fans and watering system were operated as described previously. The system was thus operated for a period of 3 days with the MEK source on, to facilitate microbial 'induction' to the VOC.

d) Filtration measurement test. Green wall unit fans and watering system were operated as described previously. The system was run for a period of $8 \mathrm{~h}$ with the MEK source on. Air samples were taken hourly, with sampling from ingoing and outgoing gas streams (i.e. eight samples from each).

e) Removal of plants.

f) Chamber loss trial (empty green wall). The system was run overnight with the MEK source on. Air sampling was performed from ingoing and outgoing chemical streams (one sample from each, at the end of this sequence). 


\section{Sampling and analysis of MEK in chamber air}

Active sampling of chamber air for MEK was carried out near the chamber inlet and at the outlet from the green wall test assembly using PTFE tubing, Tenax TA $₫$ sorbent tubes (length $3.5 \mathrm{in}$.; internal diameter $0.25 \mathrm{in}$.) and sampling pumps (Gilian LFS 113 DC low flow samplers) calibrated using a Mesalabs Bios Defender 520 flow meter. Typical flow rate was $200 \mathrm{~mL} / \mathrm{min}$. MEK trapped on the adsorbent tubes was quantified by automated thermal desorption and gas chromatography (Perkin Elmer Analytical TD/GC) using flame ionisation detection (FID). This analytical method is as prescribed in the International Standard BS ISO 16000-6 (BS ISO 2011). The concentration of MEK was determined using a reference calibration factor, with toluene as reference compound. Concentrations ranging from 3 to $3000 \mathrm{ng}$ were spiked on to tubes and analysed for the purposes of calibration. The LOQ for MEK was $10 \mathrm{ng}$ on the tube.

\section{Data analysis}

Data are displayed as means and standard errors (SEM). Average inlet versus outlet concentrations of MEK at each hourly interval were compared using general linear model repeated-measures analysis of variance (RM ANOVA). Data were Ln transformed to improve homogeneity of variance. Control sample analyses, which compared inlet to outlet MEK concentrations without a biofilter present, were performed using a paired-samples $t$ test, based on 1000 bootstrap samples. Analyses were performed using SPSS v20.0.0, IMB Corp, 2011.

To allow comparison with other biofiltration and mechanical air cleaning systems, the clean air delivery rate (CADR) of the system was calculated, which represents the clean airflow rate produced by the system, based solely on the removal of MEK. As the current work was based on pollutant reduction of a continuous VOC source rather than static chamber draw down, exponential pollutant decay rates were unavailable for the determination of CADR (see Wang et al. 2012), and these were therefore calculated as per Chen et al. (2005):

$\mathrm{CADR}=Q_{\mathrm{ac}} \eta_{\mathrm{ac}} E_{\mathrm{d}}$

where $Q_{\mathrm{ac}}$ is the air cleaner flow rate $\left(\mathrm{m}^{3} \mathrm{~h}^{-1}\right), \eta_{\mathrm{ac}}$ is the MEK removal efficiency (\%), and $E_{\mathrm{d}}$ is the 'shortcircuiting factor', which is equal to the inlet MEK concentration/average MEK concentration in the test chamber, which was approximated at 1 in the current experiment due to thorough mixing of the chamber atmosphere with oscillating fans.

\section{Results and discussion}

The testing conditions and results are summarised in Table 1. There was a significant difference between inlet and outlet concentrations of MEK during filtration measurement trials (Fig. 3; RM ANOVA, $F=220.05, p=0.000$ ), indicating that the biowall including plants had a significant capacity to reduce VOC concentrations. Inlet concentrations of $33.9 \pm 0.54 \mathrm{ppbv}$ of MEK were reduced to $14.7 \pm 0.30 \mathrm{ppbv}$ after a single pass through the biofilter, representing a single-pass removal efficiency (SPE) of $56.6 \pm 0.86 \%$. There were no significant empty chamber control MEK losses (paired-samples $t$ test, bootstrap $p=0.634$ ), indicating excellent chamber integrity relative to previous work, where considerable chamber losses were detected (e.g. Irga et al. 2013; Wood et al. 2002). There were no significant differences between sample time points (RM ANOVA, $F=2.068$, $p=0.198$ ), indicating a consistent VOC removal effect, with no change in efficiency over the 8-h testing period.

The biofiltration device produced a CADR, or airflow, from which MEK had been removed, of 28.3 or $18.9 \mathrm{~m}^{3} \mathrm{~h}^{-1} \mathrm{~m}^{-2}$ green wall area. A single biofilter of the type tested here would thus provide almost one air change per hour $(\mathrm{ACH})$ for a room of $30 \mathrm{~m}^{3}$. This experiment represents the first instance that the single-pass, flow through VOC removal efficiency by an active green wall in a room-sized chamber has been performed, and is also one of few studies to document the phytoremediation of volatilised MEK.

Chen et al. (2005) compared the single-pass, large chamber pull-down removal efficiency of a prototype active botanical biofilter with several physiochemical and mechanical air cleaning devices for 17 VOCs, including MEK. Removal efficiencies for MEK ranged from 0 to $41.1 \%$, with the tested botanical system surprisingly being found $<15 \%$ efficient for MEK removal. The system tested in the current work would appear to outperform all of those tested by Chen et al. (2005) for MEK removal efficiency, although no functionally valid comparisons can be made for CADR, as Chen et al. (2005) do not supply the filtration surface area of their test systems.

The removal of various other VOCs by active green walls has been demonstrated previously. Wang (2011) detected $\sim 38 \%$ SPE for total volatile organic compounds (TVOCs) as toluene equivalents and a $90 \%$ SPE for formaldehyde, the greater magnitude of this result being attributed to dissolution of the gas in the moist filter bed of this system, the authors observing that higher moisture levels were associated with greater formaldehyde removal rates. It is apparent that VOC single-pass efficiency rates are strongly related to the solubility of the test VOC, with lower rates for nonpolar VOCs (e.g. toluene, solubility $0.052 \mathrm{~g} .100 \mathrm{~mL}^{-1}$ ), moderate rates for moderately polar VOC (e.g. MEK, 27.5 g. $100 \mathrm{~mL}^{-1}$ ), and high efficiency for polar VOC removal (e.g. formaldehyde, solubility 400 g. $100 \mathrm{~mL}^{-1}$ ). Lee et al. (2015) tested the SPE of an active biofiltration system for the removal of xylene, 
Table 1 Summary of testing conditions and results

\begin{tabular}{lllll}
\hline Test ID & Target values & Trial 1 & Trial 2 & Trial 3 \\
\hline Mean chamber airflow rate, $\mathrm{m}^{3} \mathrm{~h}^{-1}$ & $50 \pm 2$ & 49.2 & 50.7 & 48.9 \\
Mean chamber temperature, ${ }^{\circ} \mathrm{C}$ & $21.5 \pm 2$ & 21.2 & 20.5 & 20.0 \\
Mean chamber relative humidity, $\%$ & $37.5 \pm 2.5$ & 37.0 & 37.3 & 37.0 \\
Inlet concentration (MEK), ppb & $30-40$ & 31.63 & 34.25 & 35.88 \\
Outlet concentration (MEK), ppb & - & 13.75 & 15.38 & 14.88 \\
Removal efficiency, \% & - & 56.5 & 55.1 & 58.5 \\
CADR, $\mathrm{m}^{3} \mathrm{~h}^{-1}$ & - & 28.3 & 27.6 & 29.3 \\
\hline
\end{tabular}

ethylbenzene, toluene, benzene (all 1 ppmv), and formaldehyde ( $2 \mathrm{ppmv}$ ), finding removal efficiencies in the range of 71.3-75\% for all VOCs except benzene (39.7\%) and formaldehyde (44.9\%). Unlike the findings of Wang (2011), the SPEs of the various VOCs tested by Lee et al. (2015) were not correlated with their relative solubilities, which could be related to substrate differences between the systems. The relative abilities of different green wall substrates for VOC removal are still unclear and clearly require further research. It has been shown that substrates with greater organic matter content, and hence bacterial density, have a greater capacity for nonpolar VOC removal than inorganic hydroculture substrates in static potted plants (Irga et al. 2013), but this effect is unlikely to occur in active biofiltration systems unless exposed to VOCs for an extended period to allow for microbial metabolic activity to occur. Conversely, highly polar formaldehyde is removed very effectively by botanical systems based on both hydroculture (Aydogan and Montoya 2011) and soil (Kim et al. 2016). Chen et al. (2005) noted that low molecular weight, highly volatile VOCs such as formaldehyde and dichloromethane are difficult to remove using physiochemical/mechanical air cleaning systems unless specific components are added to these systems (e.g. activated alumina impregnated with potassium permanganate), and as such, it appears that biofiltration may be a practical means of mitigating these pollutants. Additionally, both the biowall system tested in the current study and the system tested by Wang
(2011) contained activated charcoal within the plant growth substrate, which is known to be effective for VOC removal (Aydogan and Montoya 2011; Chen et al. 2005). Given that VOC removal by activated carbon is a physiochemical process, it is unlikely that the SPEs detected in the current work and by Wang (2011) could be replicated in systems that are solely reliant on biological processes for VOC mitigation. Activated carbon VOC saturation has been identified as a concern for long-term use in air filters (Aydogan and Montoya 2011); however, Wang's (2011) system retained its VOC removal capacity for 300 days, and thus, this effect may not be detrimental at the low TVOC concentrations generally encountered indoors. The longevity of the substrate tested in the current work for VOC saturation was not assessed, nor was plant tolerance to VOC exposure quantified, as the botanical component of the system was replaced between test treatments. Thus, the findings presented are limited to short-term effects, and it is recommended that long-term testing be a part of future development of air phytoremediation systems.

Active biofilter air pollutant remediation trials have not been performed consistently throughout the literature, limiting the capacity to make objective comparisons between system operational components and parameters. Darlington et al. (2001) tested the inlet versus biofiltered outlet VOC concentrations for a hydroponic biofiltration system in situ in a commercial building, recording efficient VOC removal at very low inlet concentrations for toluene, o-xylene, and
Fig. 3 Results from three single-pass efficiency trials for biowall MEK removal. Data are means $\pm \mathrm{SE}, n=3$

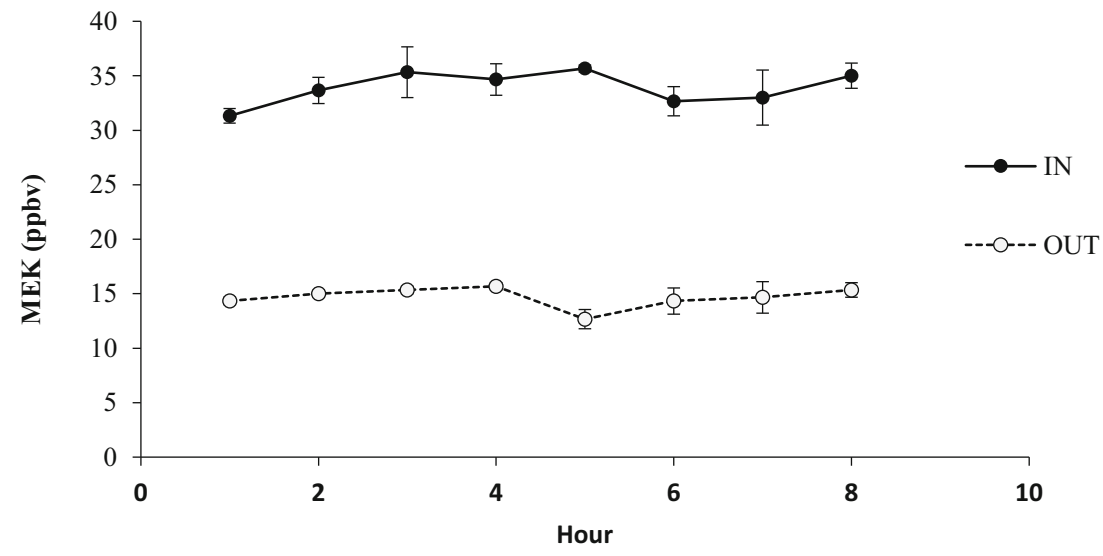


ethylbenzene. Variations in VOC removal efficiency were detected for both changes in temperature and ventilation rate, again indicating that a consistent and standardised approach to studying systems as used in the current work is required.

Wang et al. (2012) compared VOC removal for three airflow rates through a hydroponic botanical biofilter, detecting a correlation between VOC removal rates and increasing airflow for both formaldehyde and toluene. The magnitude of the increased rate, however, was relatively minor: the lowest airflow trials were still capable of removing significant quantities of both VOCs. Airflow rate was not varied in the current work, and the system was tested only at its operational airflow rate of $16 \mathrm{~L} \mathrm{~s}^{-1} \mathrm{~m}^{-2}$ green wall, which was a level determined by the green wall manufacturers to represent a practical compromise between atmosphere-substrate exposure and substrate water loss and consequent irrigation requirements. The effectiveness of the trialled airflow rate has thus not been optimised for pollutant draw down and could possibly be subject to improvement.

Plant type may also play a role in forced-air biowall VOC removal. Comparisons of the VOC removal efficiency between different plant species have been performed only for traditional potted plant systems. Liu et al. (2007) reported that the best performing plants for VOC removal were Hemigraphis alternata, Tradescantia pallida, Hedera helix, Asparagus densiflorous, Hoya camosa, and Crassula portulacea, whilst Aydogan and Montoya (2011) recorded a fourfold difference between the most (Chrysanthemum morifolium) and least (H. helix) efficient species that these authors tested for formaldehyde removal. Similarly, Wolverton and Wolverton (1993) found an almost tenfold difference in VOC removal rates between their most effective (Nephrolepsis exaltata, C. morifolium, Phoenix roebelenii, and Dracaena deremensis) and least effective (Sansevieria trifasciata, Aloe barbandensis) species amongst 33 plants tested, although these results were confounded by the use of different pot sizes amongst different plant species. Thus, whilst systems containing some species may be capable of faster VOC removal rates, all of the 120 plant species that have been tested to date (Soreanu et al. 2013) have had the capacity to remove VOCs with reasonable efficiencies (e.g. Dela Cruz et al. 2014b; Pipal et al. 2012; Wolverton et al. 1989). When considered alongside the low levels of VOCs generally found in indoor air, there appears to be no compelling evidence to suggest that VOC removal would be greatly influenced by plant choices. However, there appear to be greater interspecies differences in formaldehyde removal amongst plant species than for other VOCs, which may influence species selection if this VOC is of concern in a specific application. The mixture of plants used in the current system, which did not include any species previously observed to demonstrate very high VOC removal efficiency, was still highly effective at MEK removal.

\section{Conclusion and recommendation for future studies}

The work presented here proposed a standardised methodological approach to test the single-pass filtration efficiency of active botanical biofiltration systems and demonstrated this approach by testing the functionality of an active green wall biofiltration system. The biofilter tested demonstrated consistent single-pass removal efficiency for the test VOC, MEK. Future research into biofiltration technology should adopt procedures that allow generalisation to real world applications, and valid comparisons to be made with other systems and operational parameters. Further, additional research is required to differentiate the removal efficiency of the substrate media and moisture content, independent from combined effects of botanical biofilters in operation.

Acknowledgements The authors acknowledge Naturvention Pty, Jyväskylä, Finland, for supplying the green wall system tested in this work. We would also like to thank the BRE IAQ, HVAC Engineering, and Lighting teams for their assistance in the testing process.

Funding This work was funded by Delos LLC.

Open Access This article is distributed under the terms of the Creative Commons Attribution 4.0 International License (http:// creativecommons.org/licenses/by/4.0/), which permits unrestricted use, distribution, and reproduction in any medium, provided you give appropriate credit to the original author(s) and the source, provide a link to the Creative Commons license, and indicate if changes were made.

\section{References}

Arif AA, Shah SM (2007) Association between personal exposure to volatile organic compounds and asthma among US adult population. Int Arch Occup Environ Health 80:711-719

Ayala A, Brauer M, Mauderly JL, Samet JM (2012) Air pollutants and sources associated with health effects. Air Quality Atmos Health 5:151-167

Aydogan A, Montoya LD (2011) Formaldehyde removal by common indoor plant species and various growing media. Atmos Environ 45:2675-2682

Bernstein JA, Alexis N, Bacchus H, Bernstein IL, Fritz P, Horner E, Li N, Mason S, Nel A, Oullette J, Reijula K, Reponen T, Seltzer J, Smith A, Tarlo SM (2008) The health effects of nonindustrial indoor air pollution. J Allergy Clin Immunol 121:585-591

International Organization for Standardization ISO 16000-3:2011 (2011) Indoor air - Part 6: Determination of volatile organic compounds in indoor and test chamber air by active sampling on Tenax TA sorbent, thermal desorption and gas chromatography using MS or MS-FID ISO 16000-20. British Standards Institute, London

European Committee for Standardization/Technical Specification (CEN/ TS) 16516: 2013 (2013) Construction products. Assessment of release of dangerous substances. Determination of emissions into indoor air. British Standards Institute, London, p 60

Centres of Disease Control and Prevention (CDC) (2017) Methyl ethyl ketone-NIOSH Workplace Safety and Health Topic. Accessed 18.09.2017 https://www.cdc.gov/niosh/docs/81-123/pdfs/0069.pdf 
Chen W, Zhang JS, Zhang Z (2005) Performance of air cleaners for removing multiple volatile organic compounds in indoor air. ASHRAE Trans 11:1101-1104

Cosnier F, Grossmann S, Nunge H, Brochard C, Muller S, Lambert-Xolin A-M, Sebillaud S, Rieger B, Thomas A, Décret M-J, Burgart M, Gaté L, Cossec B, Campo P (2017) Metabolism of inhaled methylethylketone in rats. Drug Chem Toxicol 1-9. http://dx.doi. org/10.1080/01480545.2017.1289220

Da Silva CFFP, Rana C, Maskell D, Dengel A, Ansell MP, Ball RJ (2016) Influence of eco-materials on indoor air quality. Green Mater 4:72-80

Darlington A, Dat J, Dixon M (2001) The biofiltration of indoor air: air flux and temperature influences the removal of toluene, ethylbenzene, and xylene. Environ Sci Technol 35:240-246

Dela Cruz M, Christensen JH, Thomsen JD, Müller R (2014a) Can ornamental potted plants remove volatile organic compounds from indoor air? - a review. Environ Sci Pollut Res 21:13909-13928

Dela Cruz M, Müller R, Svensmark B, Pedersen JS, Christensen JH (2014b) Assessment of volatile organic compound removal by indoor plants - a novel experimental setup. Environ Sci Pollut Res 21:7838-7846

Macdonald Gibson JM, Brammer AS, Davidson CA, Folley T, Launay FJP, Thomsen JTW (2013). Burden of disease from indoor air pollution. In: MacDonald Gibson J, Brammer A, Davidson C, Folley T, Launay F, Thomsen J (eds) Environmental burden of disease assessment. Springer Netherlands, Dordrecht, pp 109-132. http://dx.doi. org/10.1007/978-94-007-5925-1

Goldstein RS, Hewitt WR, Hook JB (2013) Toxic interactions. Academic Press Inc, San Diego

Irga PJ, Torpy FR, Burchett MD (2013) Can hydroculture be used to enhance the performance of indoor plants for the removal of air pollutants? Atmos Environ 77:267-271

Kim KJ, Kim HJ, Khalekuzzaman M, Yoo EH, Jung HH, Jang HS (2016) Removal ratio of gaseous toluene and xylene transported from air to root zone via the stem by indoor plants. Environ Sci Pollut Res 23: $6149-6158$

Lai HK et al (2004) Personal exposures and microenvironment concentrations of $\mathrm{PM}_{2.5}, \mathrm{VOC}, \mathrm{NO}_{2}$ and $\mathrm{CO}$ in Oxford, UK. Atmos Environ 38:6399-6410

Lawin H, Fanou LA, Hinson V, Wanjiku J, Ukwaja NK, Gordon SB, Fayomi B, Balmes JR, Houngbegnon P, Avokpaho E, Sanni A (2017) Exhaled carbon monoxide: a non-invasive biomarker of shortterm exposure to outdoor air pollution. BMC Public Health 17:320

Lee CH, Choi B, Chun MY (2015) Stabilization of soil moisture and improvement of indoor air quality by a plant-biofilter integration system. Kor J Hort Sci Technol 33:751-762

Liu Y-J, Mu Y-J, Zhu Y-G, Ding H, Crystal Arens N (2007) Which ornamental plant species effectively remove benzene from indoor air? Atmos Environ 41:650-654

Lu Y, Liu J, Yoshino H, Lu B, Jiang A, Li F (2012) Use of biotechnology coupled with bake-out exhaust to remove indoor VOCs. Indoor Built Environ 21:741-748

Mitchell B (2013) Building materials can be a major source of indoor air pollution. Occup Health Saf 82:62-64

Occupational Safety and Health Administration (OSHA) (2017) United States Department of Labor, Regulations and Standards 1910 Occupational Saftey and Health Standards, Subpart Z, Standard Number 1910.1000 Table-z-1-Limits for Air Contaminants. https:// www.osha.gov/pls/oshaweb/owadisp.show_document?p_table= STANDARDS\&p_id=9992. Accessed 20/10/2017

Orwell RL, Wood RA, Tarran J, Torpy FR, Burchett M (2004) Removal of benzene by the indoor plant/substrate microcosm and implications for air quality. Water Air Soil Pollut 157:193-207

Orwell RL, Wood RA, Burchett MD, Tarran J, Torpy F (2006) The potted-plant microcosm substantially reduces indoor air VOC pollution: II. laboratory study. Water. Soil and Air Pollution 177:59-80
Pipal AS, Kumar A, Jan R, Taneja A (2012) Role of plants in removing indoor air pollutants. In: Chemistry of phytopotentials: health, energy and environmental perspectives. pp 319-321. https://doi.org/

Ren H, Koshy P, Chen W-F, Qi S, Sorrell CC (2017) Photocatalytic materials and technologies for air purification. J Hazard Mater 325:340-366

Revah S, Morgan-Sagastume JM (2005) Methods of odor and VOC control. In: Shareefdeen Z, Singh A (eds) Biotechnology for odor and air pollution control. Springer, Berlin Heidelberg, pp 29-63. https://doi.org/10.1007/3-540-27007-8 3

Rodgers K, Hutzel W, Dana M, Handy R (2012) Can plants save money: a look at the biowall. International High Performance Buildings Conference. West Lafayette, Indiana

Rumchev K, Spickett J, Bulsara M, Phillips M, Stick S (2004) Association of domestic exposure to volatile organic compounds with asthma in young children. Thorax 59:746-751

Siswanto D, Chhon Y, Thiravetyan P (2016) Uptake and degradation of trimethylamine by Euphorbia milii. Environ Sci Pollut Res 23: 17067-17076

Soreanu G, Dixon M, Darlington A (2013) Botanical biofiltration of indoor gaseous pollutants - a mini-review. Chem Eng J 229:585-594

Steinemann A (2015) Volatile emissions from common consumer products. Air Qual Atmos Health 8:273-281. https://doi.org/10.1007/ s11869-015-0327-6

Su F-C, Mukherjee B, Batterman S (2011) Trends of VOC exposures among a nationally representative sample: analysis of the NHANES 1988 through 2004 data sets. Atmos Environ 45:4858-4867

Thomas CK, Kim KJ, Kays SJ (2015) Phytoremdiation of indoor air. Hortscience 50:765-768

Torpy FR, Zavattaro M, Irga PJ (2016) Green wall technology for the phytoremediation of indoor air: a system for the reduction of high $\mathrm{CO}_{2}$ concentrations. Air Qual Atmos Health 5:151-167

U.S. EPA (2014) The inside story: a guide to indoor air quality. https:// www.epa.gov/indoor-air-quality-iaq/inside-story-guide-indoor-airquality. Accessed 19/01/2017

Wang Z (2011) Dynamic botanical filtration system for indoor air purification. Ph.D. dissertation, Syracuse University

Wang Z, Pei J, Zhang JS (2012) Modeling and simulation of an activated carbon-based botanical air filtration system for improving indoor air quality. Build Environ 54:109-115

Wang F, Li C, Liu W, Jin Y, Guo L (2014) Effects of subchronic exposure to low-dose volatile organic compounds on lung inflammation in mice. Environ Toxicol 29:1089-1097

Waring MS (2016) Bio-walls and indoor houseplants: facts and fictions. In: Microbiomes of the built environment: from research to application, Meeting \#3, University of California, Irvine

Wolverton BC, Wolverton JD (1993) Plants and soil microorganisms: removal of formaldehyde, xylene, and ammonia from the indoor environment. J Miss Acad Sci 38:11-15

Wolverton BC, Johnson A, Bounds K (1989) Interior landscape plants for indoor air pollution abatement. National Aeronautics and Space Administration, Davidsonville

Wood RA, Orwell RL, Tarran J, Torpy F (2002) Potted plant-growth media: interactions and capacities in removal of volatiles from indoor air. J Environ Hortic Sci Biotec 77:120-129

World Health Organisation (W.H.O) (2014) Burden of disease from ambient air pollution for 2012. The World Health Organisation, Geneva

Xu Z, Wang L, Hou H (2011) Formaldehyde removal by potted plant-soil systems. J Hazard Mater 192:314-318

Zaleski RT, Pavkov KL, Keller LH (2007) Methyl ethyl ketone safety characterization for infants and children: assessment in the USEPA Voluntary Children's Chemical Evaluation Program. Hum Ecol Risk Assess Int J 13:747-772

Zhang JS, Mittelmark M, Wang Z (2011) Air Cleaning Technologies for Indoor Air Quality (ACT-IAQ): growing fresh and clean Air FINAL SUMMARY REPORT. Building Energy and Environmental Systems Laboratory. Syracuse University, New York 